\title{
The Perception of Local Community towards the Impact and Support of Volunteer Tourism in Tioman Island
}

\author{
Nor Asmalina Mohd Anuar, Zaharah Yatin, Khairul Mohd Azemi
}

To Link this Article: http://dx.doi.org/10.6007/IJARBSS/v12-i1/11848

DOI:10.6007/IJARBSS/v12-i1/11848

Received: 07 November 2021, Revised: 12 December 2021, Accepted: 27 December 2021

Published Online: 16 January 2022

In-Text Citation: (Anuar et al., 2022)

To Cite this Article: Anuar, N. A. M., Yatin, Z., \& Azemi, K. M. (2022). The Perception of Local Community towards the Impact and Support of Volunteer Tourism in Tioman Island. International Journal of Academic Research in Business and Social Sciences, 12(1), 678 -689.

\section{Copyright: () 2022 The Author(s)}

Published by Human Resource Management Academic Research Society (www.hrmars.com)

This article is published under the Creative Commons Attribution (CC BY 4.0) license. Anyone may reproduce, distribute, translate and create derivative works of this article (for both commercial and non0-commercial purposes), subject to full attribution to the original publication and authors. The full terms of this license may be seen at: http://creativecommons.org/licences/by/4.0/legalcode

\section{Vol. 12, No. 1, 2022, Pg. $678-689$}

Full Terms \& Conditions of access and use can be found at http://hrmars.com/index.php/pages/detail/publication-ethics 


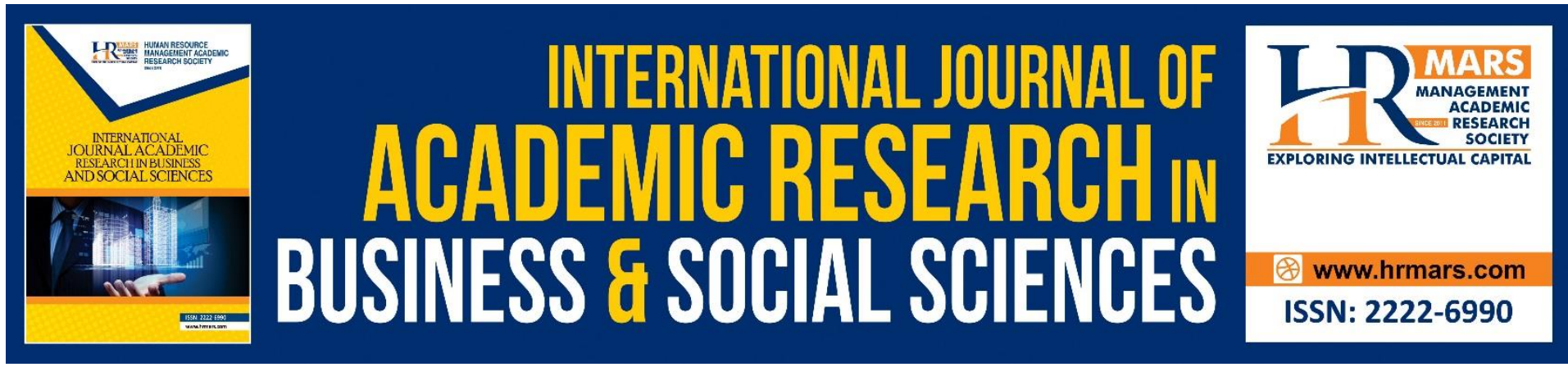

\title{
The Perception of Local Community towards the Impact and Support of Volunteer Tourism in Tioman Island
}

\author{
Nor Asmalina Mohd Anuar ${ }^{1}$, Zaharah Yatin², Khairul Mohd \\ Azemi ${ }^{3}$ \\ ${ }^{1,2}$ Faculty of Hotel and Tourism Management Universiti Teknologi MARA, Selangor, ${ }^{3}$ Tourism \\ and hospitality Department, Plotekn ik Hulu Terengganu, Terengganu
}

\begin{abstract}
This study aims to investigate the perception and impact of volunteer tourism in Tioman Island. The local community perceptions of tourism activities may influence their support and future participation. Specifically, the paper includes a review of research in the scope of volunteer tourism, tourism impact and local community support. The existing literature profoundly supports the necessity of volunteer tourism in the local community. Kampung Juara (Juara Village), Tioman Island was chosen as the research setting, and 162 local communities were surveyed. This study discovered that the local community's perceptions of the impacts of volunteer tourism positively influenced their support in future volunteer tourism projects and development. Implications were discussed concerning the need for volunteer tourism organisations to include a variety of community stakeholders in the volunteer tourism development process.
\end{abstract}

Keywords: Volunteer Tourism, Tourism Impact, Local Community, Local Support

\section{Introduction}

Before Pandemic Covid19, which affects global tourism development, the tourism industry experienced an increase (Lee \& Oh, 2018) and substantially improved what is identified as volunteer-oriented tourism. Volunteer tourism is at present a vigorous form that emphasises sustainable tourism. According to Wearing and McGehee (2013), volunteer tourism is viewed as "an expanding tourism niche, an alternative form of tourism, or a sign of major sociocultural change." Many authors also perceived volunteer tourism as a form of alternative tourism and labelled this form of tourism that relates to new-found moral, pro-poor, social, cultural, generosity, ethics and responsible (Callanan \& Thomas, 2005; Lyons et al., 2008, Butcher \& Smith, 2010; Lyons et al., 2012; Rogerson, 2011). Butcher \& Smith (2010) indicated that volunteers who participate in volunteer tourism have aimed to change or improve. Meanwhile, Scheyvens (2002) viewed that volunteer tourism may give something in return and achieve something more momentous than a pleasure-filled, hedonistic holiday. In some literature, the definition highlights volunteer tourism within the context of holidays. However, for this study, Müller's framework is more relevant, as the current short-term volunteering that focuses on voluntary engagement to make a difference with the main intention to 
improve the economy, social or ecological situation (Müller \& Reeh, 2010; Reeh \& Müller, 2012).

According to Goeldner and Ritchie (2009), tourists have a variety of pleasurable travel destination attractions based on culture, recreation, events, entertainment, and nature products. Thousands of tourists are pleased with the fascination of island's physical and climatic characteristics, as supported by Baum (1995) cited in Stylidis, Terzidou and Terzidis (2007). Keane (1992) mentioned that tourists are mesmerised with the island since they want to have a sense of aloneness and reserve silence and peace from the hassle and bustle of daily life and activities. Nowadays, tourists prefer to travel to the natural attractions, mainly visiting the islands in Malaysia and other countries such as Indonesia and Philippines. Malaysia is popular among tourists for its splendid nature, especially the clear blue water with white sandy beaches. In Malaysia, 42 islands are gazetted as marine parks under the Establishment of Marine Parks Malaysia Order in the Fisheries Act 1985, encompassing a total area of $2,486.13 \mathrm{sq} \mathrm{km}$. It is estimated that 800,000 tourists visit Malaysia's award-winning marine parks (Department of Marine Park Malaysia, 2019).

Tioman Island has been a preferred destination by the allocentric group such as volunteer tourists since early 1970 (Mustapha et al., 2013). It is evident that the development of conservation-based volunteer tourism in Tioman Island is mostly done by the NonGovernment Organization (NGO). In some previous studies, most of the local community agreed that the area of Tioman Island was caused by pollution, littering and other island tourism activities that slowly has changed the environmental condition and surroundings (Carr et al., 2007; Hanafiah et al., 2013; Bradley \& Yee, 2015; Chia et al., 2018). Positively due to that, there are some conservation-based volunteer tourism initiatives implemented in the area. However, some locals may have sceptical perceptions about the projects. They are concerned that the project's activities may jeopardise their safety and security. These unenthusiastic perceptions may influence their support for volunteer tourism projects in Tioman Island. Therefore, it is important to comprehend the local community's perceptions of the impacts of volunteer tourism that affect their support on volunteer tourism programs and projects. Muurmans (2011) supports community support that community support is essential for the long-term accomplishment and existence of any local conservation-based volunteer tourism project. The objectives of this study are: 1) to examine the local community support towards the impact of economic, socio-cultural and environmental on volunteer tourism 2) to investigate the relationship between those impacts and local community support on volunteer tourism.

\section{Literature}

\subsection{Tioman Island}

Tioman Island is a popular tourist island-based destination in the East Coast of Peninsular Malaysia. The island has various marine resources and attracted many domestic and international tourists in Malaysia. Among 42 gazetted islands as marine parks, Tioman Island is one of the 10 most magnificent islands in the world. In terms of location, Tioman Island is in the state of Pahang and is the largest island in the groups of nine islands (Tioman, Tulai Labas, Sepoi, Seri Buat, Tokong Bahara, Gut, Cebeh and Sembilang) which establish the Tioman Island Marine Park.

Tioman Island is situated nearly 32 nautical miles east of Tanjung Gemuk, Pahang. There are 9 villages in Tioman Island; however, Kampung Juara was chosen as the setting for this study, and the respondents involved the local community in the area. Kampung Juara has various 
interesting tourism activities such as watersports, diving, swimming, surfing, trekking, cycling, rock climbing, turtle watching and rehabilitation and many more. With great efforts by Tioman Development Authority (TDA), it has changed the figure of tourists' arrival to Tioman Island, particularly Kampung Juara, which is very popular among tourists. TDA has promoted the island as a tourist destination with great marketing, advertising, and updating a lot of information about community activities and tourism programs (Norhafiza \& Ku'Azam, 2017).

\subsection{Volunteer Tourism}

Volunteering refers to activity accomplished through a non-profit organisation or ongoing project that benefits the community and the volunteer. It is the volunteers' own free will and without any pressure and financial remuneration (Volunteer Australia, 2009). Volunteer tourism is part of a travel experience where the travellers devoted her/his portion of time to voluntary service at the destination. It may involve the environment, infrastructure or residents, with determination to create positive impacts on the destination (Bakker \& Lamoureux, 2008). McGehee and Andereck (2009) found that volunteer tourists are involved in different types of work, including religious mission trips, environmental conservation, community welfare, business development, healthcare, and construction.

United Nations acknowledged volunteerism as an essential element of any approach designed to reduce poverty, sustainable development and social integration (Bakker \& Lamoureux, 2008). Besides, Scheyvens (2002) argued that volunteer tourism is different from mass tourism because Western tourists have spent and visited the Third World countries to support conservation work and development work, and lastly, to fulfill their self-indulgent holiday. Volunteer tourism also enriched the communication between the local community and volunteers worldwide with better thought in the culture. In addition, Wearing (2004) argued that scholars claim that volunteer tourism is a part of sustainable tourism practice because tourists and the local community enjoy the advantages and nurture the significant and pleasing connection between tourists and the local community.

Volunteer tourism is perceived as attractive prospects for developing countries and advancing stakeholders in achieving economic and social goals and knowledge sharing, promoting knowledge transfer, and contributing something useful to the public (Ruhanen, Cooper \& Fayos- Solá, 2008). Furthermore, the volunteers and local communities receive benefits from volunteer tourism. Therefore, Ruhanen, Cooper, and Fayos- Solá (2008) suggested volunteer tourism may affect the local community's economic, socio-culture and environmental features and may determine whether to continue to support any additional volunteer tourism programs and activities (McGehee \& Andereck, 2009). However, if the cost is greater than the benefits of volunteer tourism, future volunteer tourism activities may be deemed negatively (Chen \& Hsu, 2001).

\subsection{The motivations of Volunteer Tourism}

Understanding the host community motivations would be the reason to sustain and continue the volunteer tourism. The involvement from them is expected to meet their needs and bring positive benefits. Community participation in tourism is crucially to be considered for the sustainability of any tourism programs (Gursoy, Chi \& Dyer, 2010; Musa, Hall \& Higham, 2004), including the volunteer tourism activities. Thus, a good and beneficial volunteer tourism projects and activities help to support a broader communication between tourism sectors and industry. In the case of Kampung Juara, the volunteer tourism activities are focused to create better positioning as one of tourism destinations in Tioman Island. This can 
benefit both the volunteers and host community especially in promoting a good destination image. Other than that, the supports of local community in volunteer tourism in vital for the planning and growth of community tourism businesses in the future. The spirit and support of volunteerism is valued in the community life and contributed to the sense of humanity (Zulhaimi, Halim \& Zawawi, 2018). The feeling of warm, sociable and hospitable from volunteer tourism activities would also create a positive reputation among the tourists and other stakeholders. Undoubtedly, there is a deviation of perceptions on the impacts by local community and they may determine whether to continue to support volunteer tourism or not. However, if the benefits of volunteer tourism are greater than the costs, most probably they would give support to these volunteer tourism activities (McGehee \& Andereck, 2008, 2009; Lepp, 2009; Choi \& Murray, 2013).

\subsection{Economic Impact}

Research by McGehee and Andereck (2009) found that volunteer tourism may affect the local economy favourably. Volunteers spent at the local hotel or rent accommodation in the area, dining in a local restaurant or stall, and buying groceries at a local grocery shop where the locals are buying. Meanwhile, in their study, Zahra and McGehee (2013) found that volunteer tourism had supported the local community economy in Barrio, Philippines, with the volunteers renting a house from them. Besides, volunteers also shopped at the same place with them. However, Holmes and Smith (2009) argued that volunteer tourism has been doubted, especially when they were assisting for a short period in a certain destination.

\subsection{Socio-cultural}

Volunteer tourism has been described as one of the practices to achieve sustainable development for the local community. Brown (2005), as cited in Ingram (2011), suggested that socio-cultural impacts are vital dimensions in volunteer tourism studies because they relate to the local community. Most volunteer tourists expect cross-culture experiences and exposure to local cultural practices that build a close relationship with the local community. The local community has started to appreciate their unique cultures and environment when tourists praise and show interest in them. It is supported by McIntosh and Zahra (2008) finding that volunteer tourism has made children in the Awatapu community appreciate and honour their Maori culture. A similar situation also occurs in the Philippines; the local community started to get involved in cultural activities and events when foreign volunteers showed interest in Filipino and their cultures (Zahra \& McGehee, 2013).

More than that, the relationship between the community and volunteer tourists has created a mutual understanding and friendship among them. Mclntosh and Zahra (2008) studied the indigenous community in New Zealand found that the relationship between the local community and volunteer tourists is positive in cultural exchange. Local communities feel delighted when foreign volunteers acknowledge their cultures. Furthermore, volunteering is a learning experience for volunteer tourists since they interact with the local community and exchange cultural knowledge (Mellett, 2010).

\subsection{Environment}

Wearing (2004) found a connection between volunteer tourism and preservation research when organisations collaborated with researchers in the human capital and financial for preservation study. Ecotourism organisation, volunteer tourism and biological researchers in Peru have benefited in collaboration with them in the term of financial and human capital 
(Brightsmith, Stronza \& Holle, 2008). In addition, the collaboration between volunteer tourism organisations and ecotourism organisations can offer long-term funding for research, particularly in Third World countries where resources are limited and biodiversity is concerned. Ellis (2003) found that ecological researchers were obtaining benefits from conservation volunteer tourism programs/projects. This includes increasing and promoting public appreciation and encouragement for environmental preservation and scientific research, persuading the actions and approaches of the society regarding the natural environment and flora and fauna, creating environmental-friendly approaches between them. Furthermore, scientists are more dedicated to research and purchasing equipment since financial assistance are available, persuading the political directive

Volunteer tourism also creates awareness among the local community regarding conservation and preservation of the environment (Rattan, 2009). Zahra and McGehee (2013) found that the local community is concerned with cleanness. They educate their community with signage as a notice to keep the area of tourism attractive and unpolluted from litter. Similar situation in Belize (Blackman, 2012), signage has been used to educate local communities regarding the importance of environment and wildlife conservation. It shows that volunteer tourism is promoting public awareness of the environment and wildlife among the surrounding community.

\section{Method}

The perceptions of the local community towards the impacts of volunteer tourism were obtained via a self-administered questionnaire. Simple random sampling was used in the data gathering process. The sampling size is 162 persons based on Krejcie and Morgan (1970) Table for Determining Sample Size. Therefore, 162 survey questionnaires were distributed to the local community in Kampung Juara (Juara Village), Tioman Island. A five-points Likert scale was used in this study. The value of 1 indicated as strongly opposed action (strongly disagree), 2 (disagree), 3 (neutral), 4 (agree) and 5 (strongly agree) as strongly supporting a decision on the scale. These scales were used to measure the local community perceptions towards volunteer tourism impacts as well as to determine support for volunteer tourism.

The content of the instrument was categorised into three sections. Section (A) is regarding the respondent socio-demographic profile. Section (B) assesses the local community's perceptions towards volunteer tourism impacts divided into three sub-segments: economic, socio-cultural, and environment. In the questionnaire, 25 items were used in Section B to assess the local community's perceptions towards volunteer tourism impacts on economic, socio-cultural and environment. Eight items were adopted and adapted from Lupoli (2013), Dillette (2012), Thanh and Viet (2012), Brida, Osti and Faccioli (2011), which assessed on the perceptions of the local community towards volunteer tourism impacts on the economy. Besides, ten items were used to measure the perceptions of local community towards the impacts of volunteer tourism on socio- cultures as well as seven items that determined the perceptions of local community towards the impacts of volunteer tourism on the environment were adapted and adopted from Thanh and Viet (2012), Brida, Osti and Faccioli (2011). Lastly, Section (C) examined the levels of support for volunteer tourism. Six items were determined local community support for volunteer tourism adopted from Brida, Osti \& Faccioli (2011), Hong Long (2012), Thanh \& Viet (2012). The measurement constructed in this study was then validated thru academic review.

The data was coded in Statistical Package of Social Science (SPSS) version 20.0 for data analyses. Exploratory Factor Analysis (EFA) was applied to gather information regarding the 
interrelationships among the variables. Then, inferential statistical analyses were performed. The following section presents the results and data analyses.

\section{Result}

The EFA results showed that Kaiser-Meyer-Olkin (KMO) statistics of 0.90 was significant at the level of .001. However, the EFA output suggested ten items need to be removed based on Hair et al. (2010) guidelines: commonality statistic (less than .50) and factor loading (less than .50), reducing the scale to 21 items. In terms of reliability analysis, the high coefficient values (ranging from .71 to .92) are attributed to the research instrumen-tation being adapted from previous studies (Hong Long, 2012; Thanh \& Viet, 2012; Brida, Osti \& Fac-cioli, 2011).

\subsection{Descriptive analysis}

Most respondents of these studies were aged between 51 years old and above ( 37.70 percent), male (59.40 percent) and Malay ethnic ( 96.40 percent). Most of the respondents are married (79.90 percent) and lived in Kampung Juara (Juara Village), Tioman Island, for 20 years and above (78.30 percent). Besides, 28.30 percent of respondents worked as tourism workers with an average income per month less than RM 1000.00 (44.20 percent) and had received secondary school education as the highest education level (50.00 percent).

\subsection{Regression analysis}

A single-step regression analysis was conducted. Three independent variables: economic, socio-cultural and environment was regressed with the dependent variable: local community support. Table 1 shows the result of the single-step regression.

Table 1. Results of Single-step Regressions

\begin{tabular}{llll}
\hline & Model 1 & Model 2 & Model 3 \\
\hline Predictors & Economic & Socio-cultural & Environment \\
\hline Std. $\beta$ & $.45^{* *}$ & $.62^{* *}$ & $.78^{* *}$ \\
$\mathrm{R}^{2}$ & .19 & .39 & .61 \\
Adj. $\mathrm{R}^{2}$ & .20 & .38 & .60 \\
$\mathrm{R}^{2}$ change & .20 & .39 & .60 \\
$\mathrm{~F}$ - Change & 32.33 & 85.32 & 209.33 \\
\hline
\end{tabular}

Note: ${ }^{*} p<0.05,{ }^{* *} p<0.01,{ }^{* * *} p<0.001$

Based on the table above, the perceptions of the local community towards the impacts of volunteer tourism on economic attributes (Model 1 ) were able to explain 19 percent $(R 2=.19$, F-Change $=32.33, p<0.001$ ) of the variance in support for volunteer tourism. The results confirmed that economic attributes $\left(\beta=.45^{* *}\right)$ positively influence volunteer tourism support. Meanwhile, in term of the socio-cultural, the results shows that socio-cultural impact (Model 2 ) has a huge influence towards community support $(R 2=.39$, F-Change $=85.32, p<0.001)$. The results confirmed that socio-cultural attributes positively impact $\left(\beta=.62^{* *}\right)$ their support for volunteer tourism. Finally, Model 3 results show that the environment attributes were able to explain 61 percent $(R 2=.61, F$-Change $=209.33, p<0.001)$ of the variance in support for volunteer tourism. The results confirmed that environmental attributes posit a strong positive influence $\left(\beta=.78^{* *}\right)$ towards support for volunteer tourism. The results show all the attributes are significantly related towards the support for volunteer tourism, with environmental impact as the most necessary attributes for the local community support. 


\section{Discussion, Implications, Conclusion and Contributions of Research}

In reviewing the perceptions of the local community towards the impacts of volunteer tourism, the assessment discovered the overall perceptions of the local community towards the consequences of volunteer tourism on economic, socio-cultural, and the environment. Initially, the volunteer tourism has been introduced as a function to improve the conditions of destination. However, this has also led to discussions and criticisms of what could be done to improve the participants and the industry as a whole. In this study, the results indicated that the overall benefits of volunteer tourism are greater than the cost for the local community. This finding was in line with the previous studies done a few years ago (McGehee \& Andereck, 2008, 2009; Lepp, 2009, Choi \& Murray, 2013 ). If the local community's perceptions of volunteer tourism's impact are more positive than negative, it may lead the local community to support it. However, adverse effects on volunteer tourism should not be neglected (McGehee \& Andereck, 2008). To enhance the support of local community, volunteer tourism organisation needs to minimise the undesirable impressions of volunteer tourism.

To conclude the main finding of this study, local community of Kampung Juara in Tioman Island has shown very positive support to volunteer tourism programs because they experienced increase in standard of living, cultural exchanges and environmental conservation. The supports were imparted from the three (3) dimensions which include economy, socio-cultural and environment. For further suggestion, selecting tourism products and activities also important to activate the perceptions of local community towards the impacts and support of volunteer tourism. For instance, the turtle conservation project as the tourism product has enriched the image of Kampung Juara among other villages in Tioman Island. From these impacts, the local community could be influenced to get more actively involved in other volunteer tourism programs in the future by considering appropriate tourism products and activities.

The local community is the key stakeholder to champion any volunteer tourism projects. In addition, the impact of volunteer tourism on economic, socio-cultural and environment affect their support for the development of volunteer tourism. Therefore, volunteer tourism organisations or project organisers should consider the long-term viewpoints of local communities when making strategy or judgments pertaining to volunteer tourism projects and programs in that particular area. Besides, those who participate can also collaborate with government and private organizations or institutions to gain additional supports and relevant resources for the betterment of the programs.

Many future studies can be explored from this research, especially to relate the participation in volunteer tourism before and after the Covid-19 pandemic. A few studies were done in Tioman Island on the local community and their support; however, the researchers have focused on different scopes, which also requires a further extension. One could focus on the research by viewing the perception towards multiple variables such as community satisfaction and influence power. The research can also cover other Island tourism destinations as their settings. Besides, a comparison between the local community and volunteer tourists' perceptions or other stakeholders, including the authorities, on the impacts of volunteer tourism might also be valuable, especially in engaging with future strategies. Additionally, a different perspective on volunteer tourism from several views of benefits may be explored. In terms of theoretical and contextual contributions, this study has significantly help to the existing knowledge on the impacts and volunteer tourism, especially from one of the communities in Malaysia as a setting that support the tourism industry. The framework also 
highlights the important variables which consists of economic, socio-cultural and environmental on volunteer tourism support. In fact, it is useful for practitioners or researchers who have interests in empirical studies which get to evaluate more on the practices and involvements of communities in volunteer tourism. For the contextual setting of volunteers and the volunteer tourism activities, it is more comprehensive than what have been described in the literatures. The internal situations of the volunteers, such as their skills or expertise that help the overall participation in volunteer tourism have also given benefits and enriched the image of local community, thus influence them to contribute and support more in the future for the tourism activities and projects in the area.

\section{References}

Bakker, M., \& Lamoureux, K. M. (2008). Volunteer tourism - International. Travel \& Tourism Analyst, 16, 1-47.

Baum, T., \& Mudambi, R., 1995, Managing Demand Fluctuations in the Context of Island Tourism, In Conlin, M.V. and Baum, T. (Eds.), Island Tourism: Management Principles and Practice, Chichester: John Wiley \& Sons Ltd.

Blackman, K. (2012). Conservation and community: The impact of volunteer ecotourism from a local perspective. (Unpublished Master thesis). King College London, UK. Retrieved from Google Scholar Database.

Bradley, P., \& Yee, S. (2015). Using the DPSIR framework to develop a conceptual model: Technical support document. US Environmental Protection Agency, Office of Research and, National Health and Environmental Effects Research Laboratory, Atlantic Ecology Division.

Brida, J. G., Osti, L., \& Faccioli, M. (2011). Residents' perception and attitudes towards tourism impacts: A case study of the small rural community of Folgaria (Trentino - Italy). Benchmarking: An International Journal, 18(3), 359-385. https://doi:10.1108/14635771111137769

Brightsmith, D., Stronza, A., \& Holle, K. (2008). Ecotourism, conservation biology, and volunteer tourism: A mutually beneficial triumvirate. Biological Conservation, 141(11), 2832-2842. https://doi:10.1016/j.biocon.2008.08.020

Brown, S. (2005). Travelling with a purpose: Understanding the motives and benefits of volunteer vacationers. Current Issues in Tourism, 8(6), 479-496. https://doi:10.1080/13683500508668232

Butcher, J., \& Smith, P. (2010). 'Making a difference': Volunteer tourism and development. Tourism Recreation Research, 35(1), 27-36.

Callanan, M., \& Thomas, S. (2005). Volunteer tourism: Deconstructing volunteer activities within a dynamic environment, In Marina Novelli (Eds), Niche Tourism: Contemporary issues, trends and cases, Oxford-Burlington (GB), pp. 183-200.

Carr, E. R., Wingard, P. M., Yorty, S. C., Thompson, M. C., Jensen, N. K., \& Roberson, J. (2007). Applying DPSIR to sustainable development. International Journal of Sustainable Development \& World Ecology, 14(6), 543-555.

Chen, J., \& Hsu, C. H. C. (2001). Developing and validating a riverboat gaming impact scale. Annals of Tourism, 28(2), 459-476.

Chia, K. W., Ramachandran, S., Ho, J. A., \& Ng, S. S. I. (2018). Conflicts to consensus: Stakeholder perspectives of Tioman Island tourism sustainability. International Journal of Business \& Society, 19. 
Choi, H. C., Murray, I. (2010). Resident attitudes toward sustainable community tourism. Journal of Sustainable Tourism, 18, 575-594.

Department of Marine Park Malaysia. (2019). Retrieved May 2019, Department of Marine Park Malaysia from: http://www.dmpm.nre.gov.my/apa-itu-taman-laut.html?uweb=jtl

Dillette, A. K. (2012). Volunteer tourism: Exploring the perceptions of Bahamian islanders and student volunteer tourists. (Unpublished Master thesis). Auburn University, Alabama. Retrieved from Google Scholar Database.

Ellis, C. (2003). Participatory environmental research in tourism - A global view. Tourism Recreation Research, 28(3), 45-55.

Goeldner, R. C., \& Ritchie, B. J. (2009). Tourism: principles, practices, philosophies (11th ed.). New Jersey: John Wiley \& Sons, Inc.

Gursoy, D., Chi, C., \& Dyer, P. (2010). Locals' Attitudes toward Mass and Alternative Tourism: The Case of Sunshine Coast, Australia. Travel Research, 49(3), 381-394.

Hair, J. F., Black, W. C., Babin, B. J., \& Anderson, R. E. (2010). Multivariate Data Analysis (7th ed.). Upper Saddle River, New Jersey: Prentice Hall.

Hanafiah, M. H., Jamaluddin, M. R., \& Zulkifly, M. I. (2013). Local community attitude and support towards tourism development in Tioman Island, Malaysia. Procedia-Social and Behavioral Sciences, 105, 792-800.

Holmes, K., \& Smith, K. (2009). Managing volunteers in tourism: Attractions, destinations and events. Elsevier. UK: Elsevier.

Long, H. P. (2012). Tourism impacts and support for tourism development in Ha Long Bay, Vietnam: An examination of residents' perceptions. Asian Social Science, 8(8), 28-39. https://doi:10.5539/ass.v8n8p28

Ingram, J. (2011). Volunteer tourism: How do we know it is 'making a difference'? In Benson, A. M. (Ed.), Volunteer tourism: Theory framework to practical Applications (211-222). New York: Routledge.

Keane, M. (1992). Case study: Strategic management of island tourism. The case of the Aran Islands. Journal of Tourism Management, 13 (4), 406-414.

Krejcie, R. V., \& Morgan, D. W. (1970). Determining sample size for research activities. Educational and psychological measurement, 30, 607-610.

Lee, J.S.-H., \& Oh, C.-O. (2018). The Causal Effects of Place Attachment and Tourism Development on Coastal Residents' Environmentally Responsible Behavior. Coastal Management, 46, 176-190.

Lepp, A. (2009). Discovering self and discovering others through the Taita Discovery Centre volunteer tourism programme, Kenya. In S. Wearing \& N. McGehee (Eds.), International Volunteer Tourism. Integrating Traveller and Community. (pp. 91-95). Oxfordshire, UK: CABI.

Lupoli, C. A. (2013). Volunteer tourism: A catalyst for promoting community development and conservation. (Unpublished Doctor of Philosophy thesis). Auburn University, Alabama. Retrieved from Google Scholar Database.

Lyons, K. D., \& Wearing, S. (2012). Reflections on the ambiguous intersections between volunteering and tourism. Leisure Sciences, 34(1), 88-93.

Lyons, K. D., \& Wearing, S. (2008). Volunteer tourism as alternative tourism: Journeys beyond otherness, In Journeys of discovery in volunteer tourism, International case study perspectives, ed. by Lyons, Kevin D. and Stephen Wearing, London, pp. 3-12.

McGehee, N., \& Andereck, K. (2009). Volunteer tourism and the "voluntoured": The case of Tijuana, Mexico. Journal of Sustainable Tourism, 17(1), 39-51. 
McGehee, N., \& Andereck, K. (2008). Pettin "the Critters": Exploring the complex relationship between volunteers and the voluntoured in Mcdowell County, West Virginia, USA and Tijuana, Mexico. In K. D. Lyons \& S. Wearing (Eds.), Journeys of Discover in Volunteer Tourism (pp.12-23). Oxfordshire, UK: CABI.

McIntosh, A., \& Zahra, A. (2008). Journey for experience: The experiences of volunteer tourists in an indigenous community in a developed nation- a case study of New Zeland. In K. D. Lyons \& S. Wearing (Eds.), Journeys of Discover in Volunteer Tourism (pp.166181). Oxfordshire, UK: CABI.

Mellett, J. (2010). For whose benefit? Host community perceptions of the role of short-term international volunteers in development. A case study of BREADS (Bangalore Rural Education and Development Society) Karnataka, India. (Unpublished Master thesis). Kimmage Development Studies Centre, Dublin University of Waterloo: Ontario, Canada. Retrieved from Google Scholar Database.

Sharif, M. N., \& T Lonik, K. A. (2017). Community involvement in tourism entrepreneurship: A case study in Tioman Island, Malaysia. International Journal of Multicultural and Multireligious Understanding, 4(5), 42.

Müller, D., \& Reeh, T. (2010). Volunteer tourism in Namibia. Zeitschriftfür Tourismuswissenschaft, 2(1), 19-36.

Musa, G., Hall, C. M., \& Higham, J. E. S. (2004). Tourism sustainability and health Impacts in High Altitude Adventure, Cultural and Ecotourism Destinations: A Case study of Nepal's Sagarmatha National Park. Journal of Sustainable Tourism, 12, 306-31.

Mustapha, N. A., Azman, I., \& Ibrahim, Y. (2013). Barriers to community participation in tourism development in island destination. Journal of Tourism, Hospitality \& Culinary Arts, 5 (1), 102-124.

Muurmans, M. (2011). Community conservation programs built to last. SWOT Report. The State of the World's Sea Turtle Volume IV.

Rattan, J. (2009). The role volunteer tourism plays in conservation: A case study of the Elephant Nature Park, Chiang Mai, Thailand. (Unpublished Master thesis). University of Waterloo: Ontario, Canada. Retrieved from Google Scholar Database.

Reeh, T., \& Müller, D. (2012). Sinnsuche und Selbsterleben im Volunteer Tourism -Das Beispiel, Harnas Wildlife Foundation / Namibia, In Hopfinger, Hans, Harald Pechlaner, Silvia Schön and Christian Antz (Eds.), Kulturfaktor Spiritualität und Tourismus. Sinnorientierung als Strategie für Destinationen (Schriften zu Tourismus und Freizeit vol. 14), Berlin, pp. 169-195.

Rogerson, C. M. (2011): Youth tourism in Africa: Evidence from South Africa, Tourism Analysis, 16(2), 105-120.

Ruhanen, L., Cooper, C., \& Fayos -Solá, E. (2008). Volunteering tourism knowledge: A case from the United Nations World Tourism Organization. In K. D. Lyons \& S. Wearing (Eds.), Journeys of Discover in Volunteer Tourism (pp. 25-34). Oxfordshire, UK: CABI.

Scheyvens, R. (2002). Tourism for Development: Empowering Communities. Essex, Prentice Hall.

Stylidis, D., Terzidou, M., \& Terzidis, K. (2007). Tourism island and its socio-economic impacts. Retrieved from mibes.teilar.gr/proceedings/2007/poster/StylidisTerzides\%20MTerzidis\%20K.pd

Thanh, T., \& Viet, H. (2012). The influence of local residents' perceptions on their support for volunteer tourism projects Case study: Sapa, Vietnam. (Unpublished Bachelor thesis). Haaga-Helia University of Aplied Science. Retrieved from Google Scholar Database. 
Volunteering Australia. (2009). Definitions and principles of volunteering. Retrieved from VolunteeringAustralia Inc.https://www.volunteeringaustralia.org/files/AOAL2F8K3S/VA\%20Definitions\%20a nd\%20 Principles\%20June\%202005.pd

Wearing, S. (2004). Examining best practice in volunteer tourism. In R. Stebbins \& M. Graham (Eds.), Volunteering as Leisure/Leisure as Volunteering: An International Assessment. Wallingford: CABI Publishing

Wearing, S., \& McGehee, N. G. (2013): Volunteer tourism: A review. Tourism Management, 38, 120-130.

Zahra, A., \& McGehee, N. G (2013). Volunteer Tourism: A Host Community Capital Perspective. Annals of Tourism Research, 42, 22-45.

Zulhaimi, N., Halim, M. S. A., \& Zawawi, M. M. A. (2018). The motives of volunteerism involvement in the tourism sector. International Journal of Academic Research in Business and Social Sciences, 8(6), 290-304. 